\title{
Continuous positive airway pressure therapy in the management of hypercapnic cardiogenic pulmonary edema
}

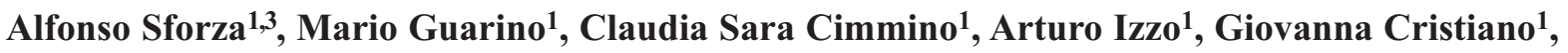 \\ Costantino Mancusi ${ }^{2}$, Gerolamo Sibilio ${ }^{3}$, Maria Viviana Carlino ${ }^{1}$ \\ ${ }^{1}$ Emergency Team, CTO Hospital, Naples; ${ }^{2}$ Federico II University Hospital, Naples; ${ }^{3}$ Coronary Care Unit, Santa Maria \\ delle Grazie Hospital, Pozzuoli (NA), Italy
}

\begin{abstract}
Continuous positive airway pressure (CPAP) therapy or noninvasive ventilation (NIV) represent the first line therapy for acute cardiogenic pulmonary edema (CPE) together with medical therapy. CPAP benefits in acute CPE with normo-hypocapnia are known, but it is not clear whether the use of CPAP is safe in the hypercapnic patients. The aim of this study is to evaluate CPAP efficacy in the treatment of hypercapnic CPE. We enrolled 9 patients admitted to the emergency room with diagnosis of acute CPE based on history, clinical examination, arterial blood gas
\end{abstract}

Correspondence: Dr. Alfonso Sforza MD, Cardiologia con UTIC, Ospedale Santa Maria delle Grazie, ASL Napoli 2 Nord, Via Domitiana, località La Schiana, 80078 Pozzuoli (NA), Italy. Tel. +39.389.7837318.

E-mail: alfosfo@hotmail.it

Contributions: AS and MVC conceived the paper and wrote the manuscript, MG, CSC, AI, GC, CM and GS contributed to the discussion and edited the manuscript.

Conflict of interest: The authors declare that they have no competing interests, and all authors confirm accuracy.

Ethics approval: All procedures performed in studies involving human participants were in accordance with the ethical standards of the Institutional Research Committee and with the 1964 Helsinki declaration and its latest amendment.

Acknowledgments: We thank all the members of the C.T.O.

Emergency Team.

Key words: Dyspnea; heart failure; blood gas analysis; hypercapnia; CPAP; lung-heart ultrasound.

Received for publication: 8 December 2020.

Accepted for publication: 24 February 2021.

${ }^{\circ}$ Copyright: the Author(s), 2021

Licensee PAGEPress, Italy

Monaldi Archives for Chest Disease 2021; 91:1725

doi: 10.4081/monaldi.2021.1725

This article is distributed under the terms of the Creative Commons Attribution Noncommercial License (by-nc 4.0) which permits any noncommercial use, distribution, and reproduction in any medium, provided the original author(s) and source are credited. analysis (ABG) and lung-heart ultrasound examination. We selected patients with hypercapnia $(\mathrm{pCO} 2>50 \mathrm{mmHg}$ ) and bicarbonate levels $<30 \mathrm{mEq} / \mathrm{L}$. All patients received medical therapy with furosemide and nitrates and helmet CPAP therapy. All patients received a second and a third $A B G$, respectively at 30 and $60 \mathrm{~min}$. Primary end-points of the study were respiratory distress resolution, $\mathrm{pCO} 2$ reduction, $\mathrm{pH}$ improvement, lactates normalization and the no need for non-invasive ventilation or endo-tracheal intubation. All patients showed resolution of respiratory distress with CPAP weaning and shift to Venturi mask with no need for NIV or endo-tracheal intubation. Serial ABG tests showed clear reduction in $\mathrm{CO} 2$ levels with improvement of $\mathrm{pH}$ and progressive lactate reduction. CPAP therapy can be effective in the treatment of hypercapnic CPE as long as the patients have no signs of chronic hypercapnia on $\mathrm{ABG}$ and as long as the diagnosis of heart failure is supported by bedside lung-heart ultrasound examination.

\section{Introduction}

Cardiogenic pulmonary edema (CPE) is among the most common causes of acute respiratory failure in the emergency department. It requires continuous positive airway pressure (CPAP) therapy or non- invasive ventilation (NIV) as first line therapy for its management together with pharmacological therapy (1). While the use of CPAP is consolidated and safe in normo/hypocapnic patients, NIV is believed to be safer in the hypercapnic population [1], although some studies have found no substantial differences in outcome between patients treated with CPAP and patients treated with NIV in this population [2]. Assuming that the pathophysiology of $\mathrm{CO} 2$ accumulation in $\mathrm{CPE}$ is different from chronic obstructive pulmonary disease (COPD) exacerbation, we tested the efficacy of CPAP in patients with hypercapnic CPE who had received a diagnosis of CPE supported by integrated lung- heart ultrasound examination [3] and who had no blood gas analytical signs of chronic hypercapnia.

\section{Materials and Methods}

We enrolled 9 patients ( 7 females) taken to the emergency room of the C.T.O. hospital in Naples for acute dyspnea in red code for the severity of respiratory failure from August 2018 to January 2020.

Based on the history, physical examination, arterial blood gas analysis and lung-heart ultrasound examination performed 
with Mindray M7 ultrasound machine by an emergency physician expert in lung ultrasound and echocardiography and according with the diagnostic pathway suggested by Carlino et al. [4], we made a diagnosis of acute CPE. We enrolled patients with hypoxia and partial pressure of carbon dioxide $(\mathrm{PaCO} 2)>50$ $\mathrm{mmHg}$. To avoid recruiting patients with chronic hypercapnia linked to COPD, we included only patients with $\mathrm{HCO}^{-}<30$ $\mathrm{mEq} / \mathrm{L}$ as suggested by Aliberti et al. [5]. All patients received medical therapy with furosemide (starting dose $40 \mathrm{mg}$ ) and nitroglycerine (starting dose $2 \mathrm{mg} / \mathrm{h}$ ) as suggested by current guidelines [1] and helmet CPAP starting with a positive end-expiratory pressure (PEEP) of between 10 and $15 \mathrm{cmH} 2 \mathrm{O}$ and an inspired oxygen fraction ( $\mathrm{FiO} 2$ ) of between $60 \%$ and $100 \%$. All patients received a second and a third blood gas analysis at 30 and $60 \mathrm{~min}$, an electrocardiogram, a chest X-ray and complete laboratory tests including brain natriuretic peptide (BNP) and C-reactive protein. The primary endpoints of the study were the resolution of respiratory distress, defined as dyspnea associated with cold sweats, use of accessory respiratory muscles and respiratory frequency greater than 25 acts per minutes, the reduction of $\mathrm{PaCO}_{2}$, the improvement of $\mathrm{pH}$, the maintenance of an arterial oxygen saturation $\geq 94 \%$, the normalization of lactate levels, the nonneed to use NIV or endotracheal intubation with mechanical ventilation. Other causes of dyspnea like pneumonia were ruled out during hospitalization. The study was conducted according to the principles of the Declaration of Helsinki. Data were analyzed using SPSS v. 21.0 (SPSS, Chicago, IL, USA). Continuous data are expressed as mean \pm 1 SD or median and categorical variables as percentages. The variations of the means of continuous variables are shown using cartesian graphs.

\section{Results}

We enrolled 9 patients ( 7 females, $78 \%$ ), 7 of them (78\%) received diagnosis of heart failure with reduced ejection fraction while 2 of them had heart failure with preserved ejection fraction, 3 of them (33\%) had atrial fibrillation. Table 1 shows the baseline characteristics of the study population. They are elderly patients presented as hypertensive $\mathrm{CPE}$ with high respiratory rate. BNP levels are high and so white blood cell count while the C-reactive protein has low values. All patients showed resolution of respiratory distress and normalization of lactates (on average $3.59 \mathrm{mmol} / \mathrm{L}$ at admission compared to 1.65 at 60 minutes) with switch to Venturi mask and no need for NIV or mechanical ventilation. Serial blood gas analysis showed progressive improvement of oxygenation (oxygen saturation was $86 \%$ on average at time 0 compared to $98 \%$ and $97 \%$ at 30 and $60 \mathrm{~min}$ ), reduction in CO2 levels (on average 65.2, 52.2 and $46.1 \mathrm{mmHg}$ respectively at time $0,30 \mathrm{e}$ $60 \mathrm{~min}$ ) and improvement of $\mathrm{pH}$ (on average 7.19, 7.28 and 7.36 respectively at time 0,30 and 60 minutes) (Figure 1 ).

\section{Discussion}

$\mathrm{PaCO}_{2}$ is strictly related to alveolar ventilation, being inversely proportional to it while it is poorly related to the characteristics of the alveolar-capillary membrane and to lung perfusion because $\mathrm{CO}_{2}$ diffusibility is twenty times greater than that of oxygen and $\mathrm{CO}_{2}$ is not bound to plasma proteins [6]. During COPD exacerba-

Table 1. Baseline characteristics of the study population.

\begin{tabular}{|c|c|}
\hline Parameter (unit of measure) & Mean $\pm S D$ (minimum-maximum) \\
\hline Age (years) & $78 \pm 6.5(70-89)$ \\
\hline Systolic blood pressure (mmhg) & $190.55 \pm 17.58(170-220)$ \\
\hline Diastolic blood pressure (mmhg) & $101.67 \pm 15.41(80-125)$ \\
\hline Heart rate (beats/minute) & $102.89 \pm 23.78(70-148)$ \\
\hline Respiratory rate (breaths/minute) & $34 \pm 4.79(28-40)$ \\
\hline Leukocytes $\left(10^{3} / \mu \mathrm{l}\right)$ & $14.98 \pm 8.74(8.39-32.66)$ \\
\hline Neutrophils (\%) & $68.95 \pm 16.25(41.6-87.4)$ \\
\hline Red blood cells $\left(10^{6} / \mu \mathrm{l}\right)$ & $4.62 \pm 0.75(3.3-5.67)$ \\
\hline Haemoglobin (g/dl) & $12.19 \pm 2.43(7.7-14.9)$ \\
\hline Platelets $\left(10^{3} / \mu \mathrm{l}\right)$ & $259.44 \pm 100.11(161-481)$ \\
\hline Troponin (ng/l) & $32.75 \pm 24.64(7.2-74.1)$ \\
\hline Glucose (mg/dl) & $233 \pm 58.54(169-343)$ \\
\hline Urea $(\mathrm{mg} / \mathrm{dl})$ & $45.22 \pm 10.34(33-62)$ \\
\hline Creatinine (mg/dl) & $1.07 \pm 0.35(0.67-1.73)$ \\
\hline Alanine transaminase $(\mathrm{u} / \mathrm{l})$ & $29.89 \pm 11.63(10-43)$ \\
\hline Sodium $(\mathrm{mmol} / \mathrm{l})$ & $140.55 \pm 2.92(137-147)$ \\
\hline Potassium $(\mathrm{mmol} / \mathrm{l})$ & $4.3 \pm 0.34(3.9-4.8)$ \\
\hline C-reactive protein $(\mathrm{mg} / \mathrm{l})$ & $10.63 \pm 6.71(2.07-24.35)$ \\
\hline & Median (minimum-maximum) \\
\hline
\end{tabular}


tion the increase of $\mathrm{PaCO}_{2}$ is mainly due to reduced alveolar ventilation with incomplete expiration caused by airflow obstruction in the distal airways and to chest pump failure. During CPE the increase of $\mathrm{PaCO}_{2}$ is mainly due to reduced alveolar ventilation caused by alveolar edema. During CPE, the increase of pulmonary capillary wedge pressure, caused by left ventricular diastolic dysfunction in both preserved or reduced ejection fraction heart failure, leads to interstitial edema that in the early stages causes hypoxemia without modifying the exchange of $\mathrm{CO}_{2}$ which on the contrary can also be reduced. With the worsening of the edema the transudate fills the alveolar cavities reducing their ventilation and, in some cases, causing complete atelectasis. This ultimately causes the worsening of hypoxia and the increase in $\mathrm{PaCO}_{2}$. During COPD exacerbation a bi-level ventilation is necessary to reduce $\mathrm{PaCO}_{2}$ because a positive end-expiratory pressure counterbalances the intrinsic positive end-expiratory pressure of COPD patients
pCO2 mean

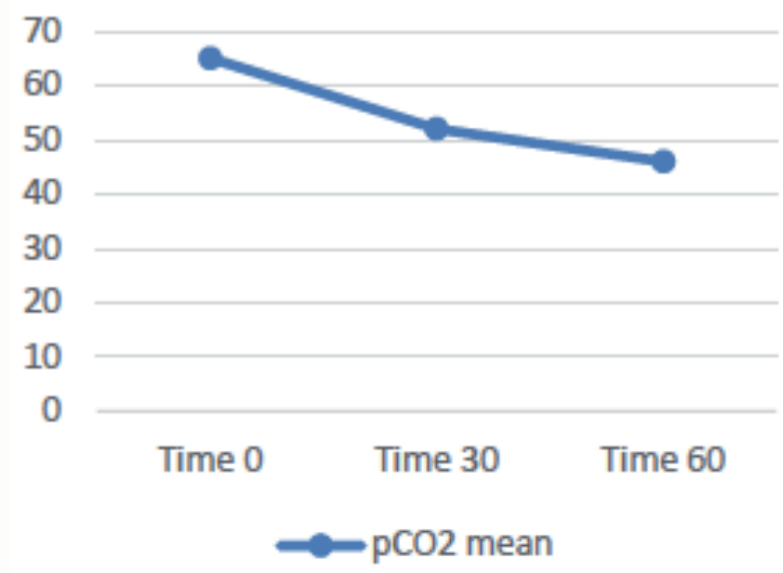

$\mathrm{pH}$ mean

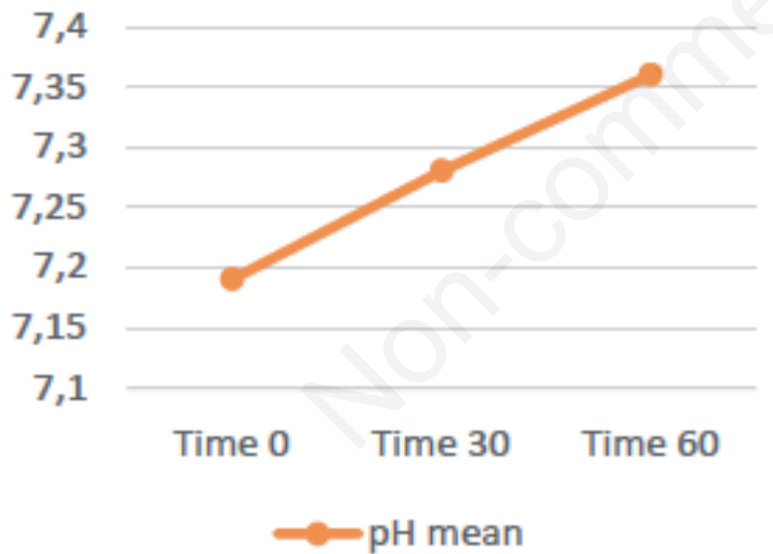

\section{Oxygen saturation mean}

100

95

90

85

80

Time 0 Time 30 Time 60

- Oxygen saturation mean

\section{Lactate mean}

4

3

2

1

0

\begin{tabular}{|l|c|c|c|}
\hline \multirow{2}{*}{ Parameter (unit of measure) } & \multicolumn{3}{|c|}{ Mean \pm SD } \\
\cline { 2 - 4 } & T0 & T30 & T60 \\
\hline Arterial oxygen saturation (\%) & $86.3 \pm 18.01$ & $98.18 \pm 1.68$ & $97.48 \pm 1.47$ \\
\hline Fraction of inspired oxygen (\%) & $60.11 \pm 19.75$ & $71.11 \pm 22.05$ & $60 \pm 23.98$ \\
\hline pH of arterial blood & $7.19 \pm 0.10$ & $7.28 \pm 0.09$ & $7.36 \pm 0.05$ \\
\hline Partial pressure of $\mathrm{CO}_{2}(\mathrm{mmHg})$ & $65.22 \pm 13$ & $52.22 \pm 7.63$ & $46.11 \pm 5.77$ \\
\hline Partial pressure of $\mathrm{O}_{2}(\mathrm{mmHg})$ & $79.11 \pm 46.95$ & $143.55 \pm 116.11$ & $98.89 \pm 49.58$ \\
\hline Bicarbonate $(\mathrm{mmol} / \mathrm{L})$ & $24.54 \pm 2.27$ & $24.49 \pm 3.24$ & $25.89 \pm 2.97$ \\
\hline Lactate $(\mathrm{mmol} / \mathrm{L})$ & $3.59 \pm 2.64$ & $2.25 \pm 2.44$ & $1.65 \pm 1.22$ \\
\hline
\end{tabular}

Figure 1. Arterial blood gas analysis at time 0 , at 30 and 60 min with graphics on variation of $\mathrm{pCO}_{2}$, oxygen saturation, $\mathrm{pH}$ and lactate. 
and a pressure support reduces the work of the respiratory muscles to win airway obstruction, helping the patient in the inspiratory phase. During CPE a continuous positive end-expiratory pressure is sufficient also in reducing $\mathrm{PaCO}_{2}$ because it improves alveolar ventilation by allowing the recruitment of imbued alveoli, promoting the reabsorption of edema and improving cardiac performance. Obviously, this type of approach requires accuracy in diagnosis. In addition to history and physical examination, blood gas analysis and point of care ultrasound are essential in the differential diagnosis in the early phases. Patients with acute on chronic respiratory acidosis have significantly higher bicarbonate levels than patients with acute respiratory acidosis. With a retrospective analysis of a study carried out in the emergency department on patients with CPE treated with CPAP [7], Aliberti et al. showed that the bicarbonate cut off to distinguish patients with acute on chronic hypercapnia from those with acute hypercapnia was $30 \mathrm{mEq} / \mathrm{L}$. Patients with pulmonary edema and bicarbonate levels $>30 \mathrm{mEq} / \mathrm{L}$ treated with CPAP had a worse clinical outcomes in comparison with patients with bicarbonate levels $\leq 30 \mathrm{mEq} / \mathrm{L}$ with a higher rate of transition from CPAP to NIV [5]. If, on the one hand, blood gas analysis gives us information on the presence of chronic hypercapnia, the integrated lung-heart ultrasound confirms or not the diagnosis of acute cardiogenic pulmonary edema. In case of pulmonary edema a diffuse bilateral lung interstitial syndrome (confluent Blines that configure a "white lung" picture) is present [8]. Heart ultrasound examination with the evaluation of left ventricular ejection fraction, left atrial dimension and left ventricular diastolic function confirms the cardiogenic origin of pulmonary edema with an accuracy of $96 \%[3,4,9]$. This approach ultimately distinguishes interstitial syndrome resulting from cardiac dysfunction from all other forms of widespread interstitial syndromes: acute respiratory distress syndrome (ARDS), pulmonary fibrosis, bilateral interstitial pneumonia, bilateral pulmonary metastasis [10]. The most important limitation of this study is the sample size which is low although it must be taken into account that the cases of hypercapnic CPE represent about $10 \%$ of the cases of CPE [7], on which we have made a further selection based on the bicarbonate levels on the first blood gas analysis. Moreover, all patients presented as hypertensive CPE. However, further studies with larger samples are needed.

\section{Conclusions}

Helmet CPAP can be used to treat hypercapnic CPE as long as there is an accurate selection of the patient who must not have starting bicarbonates greater than $30 \mathrm{mEq} / \mathrm{L}$ and must have a diagnosis of acute heart failure supported by integrated lung-heart ultrasound examination.

\section{References}

1. Mebazaa A, Yilmaz MB, Levy P, et al. Recommendations on pre-hospital \& early hospital management of acute heart failure: a consensus paper from the HF Association of the European Society of Cardiology, the European Society of Emergency Medicine and the Society of Academic Emergency Medicine. Eur J Heart Fail 2015;17:544-58.

2. Bellone A, Vettorello M, Monari A, et al. Noninvasive pressure support ventilation vs. continuous positive airway pressure in acute hypercapnic pulmonary edema. Intensive Care Med 2005;31:807-11.

3. Sforza A, Mancusi C, Carlino MV, et al. Diagnostic performance of multi-organ ultrasound with pocket- sized device in the management of acute dyspnea. Cardiovasc Ultrasound 2017; $15: 17$.

4. Carlino MV, Paladino F, Sforza A, et al. Assessment of left atrial size in addition to focused cardiopulmonary ultrasound improves diagnostic accuracy of acute heart failure in the Emergency Department. Echocardiography 2018;35:785-91.

5. Aliberti S, Brambilla AM, Cosentini R. Noninvasive ventilation or continuous positive airway pressure in pulmonary edema patients with respiratory acidosis? Look at the bicarbonates. Intensive Care Med 2011;37:2050-1.

6. Wagner PD. The physiological basis of pulmonary gas exchange: implications for clinical interpretation of arterial blood gases. Eur Respir J 2015;45:227-43.

7. Aliberti S, Piffer F, Brambilla AM, et al. Acidemia does not affect outcomes of patients with acute cardiogenic pulmonary edema treated with continuous positive airway pressure. Crit Care 2010;14:R196.

8. Sforza A, Carlino MV, Guarino M, et al. Anterior vs lateral symmetric interstitial syndrome in the diagnosis of acute heart failure. Int J Cardiol 2019;280:130-2.

9. Ferre RM, Chioncel O, Pang PS, et al. Acute heart failure: the role of focused emergency cardiopulmonary ultrasound in identification and early management. Eur J Heart Fail 2015;17:1223-7.

10. Mancusi C, Carlino MV, Sforza A. Point-of-care ultrasound with pocket-size devices in emergency department. Echocardiography 2019;36:1755-64. 